\title{
Regional Sports Tourism Networks: A Conceptual Framework
}

\section{Hagen Wäsche \& Alexander Woll}

Sports tourism is a widespread phenomenon with significant social, economic and ecological impacts. However, on an academic level sports tourism is a relatively new field of research. As a consequence, there is a relative dearth of work on theoretically informed explanations of the sports tourism phenomenon. This is particularly true for organizational aspects of sports tourism. To overcome this gap in research, a conceptual framework has been developed which provides a theoretically grounded perspective on the organizational structure of regional sports tourism (RST). Drawing on a theory of social networks, RST is considered as an interorganizational network based on mutual trust among involved actors. Three functional mechanisms of such a network of RST - cooperation, emergence and innovation - explaining the causal logic of this form of organization will be discussed. The concept of a RST network, presented in this paper, enables a theoretical explanation and understanding of individual action and collective structure in RST. Moreover, it provides a comprehensive framework for the operationalization and empirical analysis of organization in RST. Finally, several implications for further research and the management of RST networks can be derived from this approach.

Keywords: Regional Sports Tourism; Cooperation; Organizational Structure; Interorganizational Network; Social Network Theory

\section{Introduction}

During the twentieth century sports tourism has developed from a privilege of the few to a significant social, economic and cultural phenomenon in the twenty-first century (Weed \& Bull, 2009). Due to the high demand for various forms of sports tourism, it has become a substantial element in almost every tourist region and an important part of socio-economic regional development. Many regions, especially in rural areas, depend on sports tourism (Tuppen, 2000: 331). In this context, the cooperation of

Hagen Wäsche and Alexander Woll are at the Universität Konstanz, Sportwissenschaft, Postfach D 30, D-78457 Konstanz, Germany. Corresponding author: Hagen Wäsche: email: hagen.waesche@uni-konstanz.de 
a very heterogeneous group of involved actors from different social systems is crucial to coordinate differing interests and enable a positive regional development. Hence, sports tourism has to be considered as more than just the intersection of sports and tourism, or a special niche of the tourism sector. Weed and Bull (2004: xv) described sports tourism as a 'unique interaction of activity, people and place', and as such it is necessary to conceive of sports tourism as a field of research in its own right. Based on this perspective, the aim of this paper is to contribute to the discussion of the theoretical analysis of organizational aspects of sports tourism.

Although sports tourism is a widespread and significant social phenomenon, there is only a comparably small body of scientific knowledge relating to it. Several authors point to the small amount of research data that has been published so far (Gibson, 2002: 34, Hinch et al., 2006: 10; Schwark, 2007: 281, Weed, 2008a: 1). In one of their recent publications, Weed and Bull (2009: 294) summarized three main issues concerning the deficient state of sports tourism research: 'a preponderance of poor quality impacts research; a lack of a clear body of theory; and a lack of methodological diversity'. This statement is also true for organizational aspects of regional sports tourism (RST). Although the organizational integration of relevant actors of sports and tourisms seems to be one of the major challenges in this field (e.g., Tuppen, 2000: 341), organizational issues have rarely been addressed in sports tourism research. The challenge of organizational integration becomes obvious considering that many diverse actors are involved in sports tourism. Private firms, public administration, non-profit sport clubs, local residents and many other actors with different goals and cultural backgrounds are part of it. Due to this complex structure in RST, intersectoral communication and cooperation among involved actors are challenging tasks. In order to understand the constitution of this relational structure and how it can be managed, a deeper insight into this matter is needed.

The first step towards a scientific understanding of the organizational structure of sports tourism is to create a theoretical foundation to explain interrelations and develop a framework for further analysis. From a managerial point of view, it is essential to know the basic interactions of conditions, structures and processes to control the development of RST concerning social, economic and ecological outcomes. From a sociological perspective, it is of special interest to know how the link between individual action and the emergence of collective structure in the form of cooperation takes place. In the following, a conceptual foundation for a deeper understanding of the organizational structure and mechanisms of RST will be developed. On the basis of a theoretically informed perspective, a framework for the explanation and analysis of RST will be provided.

For this purpose, the current state of research on general theory-building in sports tourism as well as on organizational aspects of sports tourism will briefly be reviewed, followed by an outline of the theoretical foundations of the concept of RST as an interorganizational network (ION). Drawing on this theory, a conceptual framework will be developed and discussed. Subsequently, aspects of a negative network development will be highlighted as well. Finally, various implications affecting theoretical, analytical and managerial aspects will be considered. 


\section{State of Research}

Although, sports tourism research has made significant progress in recent years, the relatively young field of study is still characterized by many deficiencies which have to be addressed. As Weed put it, there is a 'clear need for conceptual, theoretical and methodological foundations for sports tourism research' (Weed, 2008b: 22). In 2006, Weed published a review on sports tourism research which showed that many of the published studies are self-referential case studies, which contribute only a little to general knowledge about the nature of sport tourism. Concerning the topics of research in sports tourism, Weed observed a clear bias towards sport events with a clear focus on impacts (Weed, 2006: 13). Aside from a methodological one-sidedness, another significant shortfall that Weed (2006: 19) points to is the large amount of atheoretical studies. To overcome the deficit of theoretically grounded work, it is necessary to develop theories which are able to explain the phenomenon of sports tourism. Gibson (2004: 259) suggests that sports tourism researchers should make use of the theories and concepts of other disciplines such as management, sociology, social psychology, geography and anthropology to explain sports tourism. As in any other interdisciplinary field of research, this is the most promising way towards a theoretically robust foundation in order to gain a deeper understanding of the unique characteristics of the subject.

Concerning the research on organizational structures of RST, the problems are the same as for sports tourism in general. As early as 1982, Glyptis described the crucial problem in the organization of sports tourism for the first time: a deficient linkage between actors of sport and tourism. Since then, this finding has been confirmed by many other researchers. In 1997, Weed and Bull showed that strategic cooperation among regional agencies of sport and tourism is only sporadic. Almost at the same time, Gibson noted that 'at a policy-level there needs to be better coordination among agencies responsible for sport and those responsible for tourism' (1998: 45). In 2002, she confirmed this statement, noting that there was still 'a lack of coordination and cooperation at a level of policy and implementation' (Gibson, 2002: 114) in sports tourism. Two years later, Richtie and Adair stated in reference to policy development and implementation in sports tourism:

Better integration between the two policy arenas and industry are crucial if the development of sport tourism is to be more effective and efficient, and benefits for both industry sectors are maximised. (Ritchie \& Adair, 2004: 14)

Summing up the research, Weed (2008a: 2) came to the conclusion that the central issue, the 'lack of integration' which was identified many years ago, is still an enduring problem in the area of sports tourism. This problem persists in the practice of organization in sports tourism as well as in the research about the organization of sports tourism. Most studies about the organization of sports tourism simply describe the link between sport and tourism rather than trying to explain and understand underlying mechanisms and processes determining the structures in RST. To reach the goal of a conceptual understanding of the relational structures of sports and tourism actors - why they cooperate or not - it is inevitable to draw on a theoretical base. 
Existing studies about organizational structures in sports tourism reveal very little theoretically informed knowledge. There are several suggestions on how to manage sports tourism on a national or regional level (e.g., Augustyn, 1996; Commonwealth of Australia, 2000; Hall, 2005; Hautbois et al., 2003), which are useful as a guide for practical matters. However, these approaches do not give a theoretically grounded explanation of the underlying structures and relations between the areas of sports and tourism.

As a matter of fact, there are only a few conceptual approaches to regional sports tourism which focus on the crucial interrelationship between involved actors and are able to provide a profound explanation. So far, the most comprehensive approach has been undertaken by Weed and Bull, who carried out several studies on the integration of sports and tourism policy (Weed, 2001; 2003; Weed \& Bull, 1997; 1998). Their seminal work led to the development of a grounded theory on the policy process for sport and tourism with the aim of explaining and providing an understanding of the problems in the policy development for sports tourism (Weed, 2005: 358). On the basis of an adapted and combined 'model of cross-sectoral policy development', drawing on the theoretical concepts of 'policy communities and issue networks' (Rhodes, 1981) and 'government-industrial relations' (Wilks \& Wright, 1987), several structural issues were highlighted which could affect the generation of a 'sport-tourism policy network' between the existing sport and tourism policy communities (Weed, 2005: 363). Accordingly, tourism policy communities are rather loose issue zones, whereas sports policy communities are closer to tight policy circles. Issue zones are structured differently from policy circles. They are, for example, characterized by an open membership without a clear leadership, whereas policy circles have a rather stable membership and a clear leadership. Structural differences like these may pose a problem concerning intersectoral collaboration.

Drawing on this model and empirical research, seven main factors affecting the relationships between sport and tourism agencies were identified. First of all, there are different ideologies like income generation or strategy which may cause conflicts. In addition, different definitions and concepts, e.g., excluding recreational sports from sports, can hinder collaboration between institutions of sport and tourism. Another important factor is the regional context. Geographical resources within a region and their potential for tourist activities naturally have a strong influence on the type and the strength relationship of sport and tourism. Other factors are government policies on sports tourism as well as different organizational structures and cultures. Finally, Weed states that in many cases there is a dependency on the commitment of individuals, be it key staff or political actors, which determines whether or not a link between sport and tourism will be established.

Weed's approach delivers a clear concept of the relation between sport and tourism. The identification of key factors influencing the development of collaboration between sport and tourism policy communities provides an informed explanation and can serve as a base for several management implications. Hence, Weed's policy model is a good starting point for a general understanding of the functioning of policy collaborations and strategic partnerships in sports tourism. However, since this concept 
focuses on policies or strategies, only public or quasi-public sport and tourism agencies within a dyadic relationship (the relationship between sport and tourism agencies) are considered. But, as explained above, in a comprehensive perspective, the sports tourism structure consists of a wide range of actors, such as non-profit sport clubs or commercial sport schools and facilities, hotels, residents and many more actors not only from the policy or public sector but also from other sectors. They are connected within a network of multiple relationships, concerning several issues of communication and cooperation within RST.

Focusing on policy development, Weed's model provides a general and theoretically grounded understanding of the structures of the policy communities (sector level) and how they might influence the policy networks (sub-sectoral level). By the nature of the approach, mainly macro- and meso-level actions are considered. As a consequence, the role of actors on the micro-level and how their actions influence the overall structure of sports tourism does not form part of Weed's consideration.

Another fruitful approach was developed by Breuer (2004) who drew on the concept of voluntary interorganizational networks (Mayntz, 1992) to explain the complexity of managing regional sports tourism. By means of a consensual network strategy, including all relevant local and regional actors, the aim of this strategy is to control the sport-touristic attractiveness of a region for the benefit of all involved actors. The network behind that strategy serves three main purposes. Firstly, it forms a structure to create consensus among the involved actors and develop an integrative strategy on sports tourism. Secondly, it mobilizes relevant actors to actively take part in the network. Finally, the network supports the implementation of regional projects in the field of sports tourism.

According to Breuer, there are seven preconditions for such a network to work successfully:

(1) A knowledge-based and integrating strategy concerning regional sports tourism.

(2) Trust and partnership as a foundation in a non-hierarchical network.

(3) Central coordination.

(4) A foreseeable benefit for all participating actors.

(5) The avoidance of rivalry.

(6) Political assertiveness.

(7) The avoidance of excessive demands on the members.

Breuer's network approach seems to be a promising way for an explanation of organization in RST. One the one hand, it includes all relevant actors and, on the other hand, it provides useful directions for the practical management of networks in sports tourism. Furthermore, this approach comprises the micro-level and gives an explanation of the emergence of collective structures through the motivation of actors who seek to increase their options. At this point, however, the approach does not go further on a theoretical level towards explaining the underlying mechanisms of a sports tourism network in depth.

However, by delivering innovative and theoretically grounded approaches, the work of Weed and Breuer provides a solid basis for a further development of a theoretical 
explanation of structures, processes and actions within regional sports tourism in this paper. The network approach opens up a promising path, since it is a widely used instrument of social research to analyze and understand organization based on relational structures. Although the network approach lacks a consistent theory and the state of network theory is still the subject of an ongoing discussion (Raab \& Kenis, 2009), it has the potential to generate further insights into the organizational structure in regional tourism (e.g., Lazzeretti \& Petrillo, 2007; Michael, 2007; Stokes, 2006). Consequently, the network approach is taken up to develop an understanding of organization in RST.

\section{Basic Structure of Organization in Regional Sports Tourism}

In order to outline a theoretical basis of RST networks, it is necessary to describe the particular characteristics of organization in RST. Considering organizational issues, there are certain structures and processes which constantly influence the very heterogeneous group of actors involved in RST.

As a matter of principle, these actors are geographically connected by the place (the region) in which they interact to produce a regional product of sports tourism. It should be noted that such a tourist region is not bound to the administrative borders of local communities. In the tourist context, a region is rather considered to be defined by cultural and economic aspects, as Bonetti et al. (2006: 113) state: 'the prevailing theory maintains that the unifying factor - that makes a competitive territorial area an autonomous entity - is its economic and cultural homogeneity, as perceived by clients, not its political border'. Lynch and Morrison (2007: 43) refer to the fact that tourism clusters or networks systems have to be considered as crossing local borders by introducing the notion of a 'local region' to refer to the spatial structure of tourist provision.

Generally speaking, a 'region' can be considered as an administrative, socio-economic or cultural geographic unit. For the purposes of this paper, a region is referred to as a coherent, medium-scale geographic area, above the local but below the state level, which is characterized by specific features ( $\operatorname{Sinz}, 1995: 805$ ). Subsequently, the terms 'region' and 'regional' are used in a functional approach to describe a coherent system of interaction in a sports tourism context. In a holistic approach, it is important not to exclude relevant actors who might not belong to a local community but who play a central role in the organization and provision of sports tourism. This corresponds to the perspective of sports tourists. Since a tourist perceives the sports tourism product as the combined offer within a region (crossing local administrative borders) he or she visits, it is necessary to apply a border-crossing perspective of organization in RST (Figure 1).

The region is the main point of reference and acts as the system of intervention and problem solving through cooperation in sports tourism. Hence, regional actors and their relationships, the dynamics between single actors and regional structures are the main focus of this consideration. Through cooperation of single actors, the product of RST is created. Simultaneously, the structures of RST as an institution 


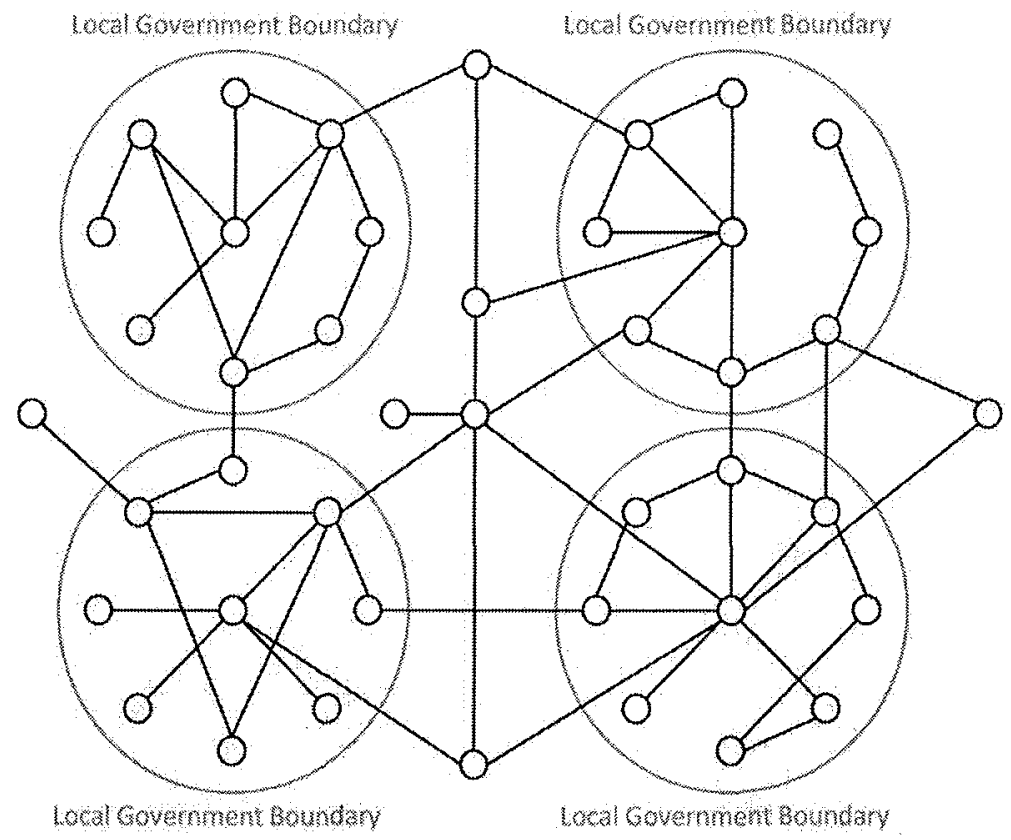

Figure 1 Regional connectedness of sports tourism actors

influence the actions of the actors involved. The question to answer is which mechanisms determine the interaction of the different actors on the individual as well as on the systems level. The understanding of this multi-level interaction is a key factor to a purposeful management of RST.

Since the relations and interactions between involved actors are the structural key element of RST, we first need to know who the involved actors are. On the supply side, there are mainly actors from a particular region who are active in the provision of sports tourism. These actors are not only individuals but also organizations, agencies, clubs and other institutions as corporate actors. As this group of RST actors is very heterogeneous, they have different cultural backgrounds and different goals. The reason for this is that they are part of different social systems. In the main, they belong to the superordinated systems of sports, economy and politics (Figure 2). While the tourism system is mainly driven by economic goals, there are - on a sublevel - further systems like health, leisure, ecology, etc. which have to be taken into account as well. Due to the different norms, values and structures of these systems, the group of actors in RST is a complex and multilayered one.

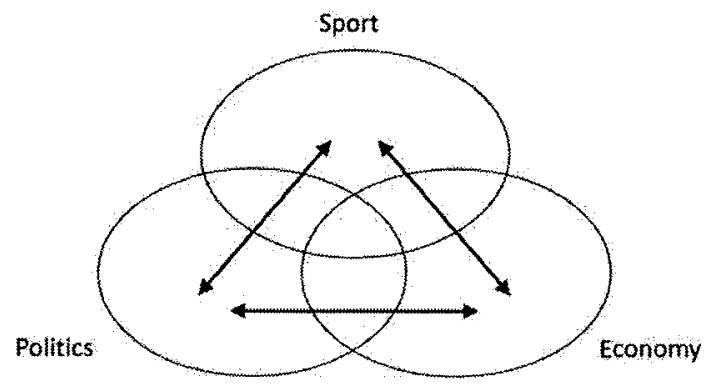

Figure 2 Superordinated social systems interacting in RST 
Although most publications or studies in sports tourism do not specify the actors explicitly, numerous relevant actors appear in the context of these publications (e.g., Augustyn, 1996; Breuer, 2004; Dreyer, 2004; Hautbois et al., 2003; Standeven \& De Knop, 1999). Tuppen (2000) in particular gives a very comprehensive overview of relevant actors. Accordingly, the core of the RST system is the resort. It incorporates actors like the local tourist organization, tourist professionals, the local council, the mayor, local residents, hotels, retailers, instructors, sport facilities, etc. Outside of the core group, there are further political actors like governmental institutions, the regional council or semi-public organizations like national or regional parks. Additionally, there are private actors like tour operators or property developers (e.g., hotel chains) who have an interest in RST. Last but not least, pressure groups like environmental protection groups have to be included. In addition to these actors, Breuer (2004) stresses the significance of scientific consultancy (e.g., universities as external sources of knowledge based on research) and non-profit sports clubs and associations (as specialized experts in sports) as actors in RST. Like the stakeholder approach, in a consideration of the organization of RST, all individuals and institutions which can affect RST or might be affected by it have to be taken into account (Freeman \& Reed, 1983: 91).

In conclusion, the actors involved in sports tourism are multiple and widespread. They are characterized by very different cultural, organizational and political backgrounds (Standeven \& DeKnop, 199: 329). Furthermore, they cannot be confined to a local community since many actors operate on a higher level. Hence, the relational structure of actors in RST is complex in the sense that it is multi-layered and border-crossing.

\section{Regional Sports Tourism as an Interorganizational Network}

As shown before, knowledge about the structural network of actors in RST is superficial and deficient. In the majority of the literature on the subject, the notion of a network to describe the cluster of RST actors is used mainly metaphorically. In this approach, the structures of RST are considered to be an interorganizational network, which is derived from the theoretical concept of social networks.

\section{The Network Approach}

There has been a long debate over whether the network approach is a perspective of considering organizational phenomena (Nohria, 1992: 3), an eclectic collection of related concepts like embeddedness, social capital or structural holes (Kilduff \& Tsai, 2007: 37), or rather a 'theory of social structures' (Degenne \& Forsé, 1999: 12). Considering the current state of network research, there are two identifiable strands.

On the one hand, there is a long history of quantitative network analysis. In 1965, Harary and Cartwright described the method, based on graph theory, which made it possible to analyse the structural embeddedness of actors within a social network. In graph theory, actors are represented by points and their relations to other actors by directed or undirected graphs. Thus, quantitative network analysis allows the 
determination of parameters like density, cohesion, centrality or the detection of structural holes in networks within friends, communities, companies, etc. Since the network approach enabled researchers to relate interactions of individuals on the micro-level with aggregate outcomes like community organization on a macrolevel, it had a significant impact on sociological theory. As Granovetter (1973: 1360) noted: 'the analysis of processes in interpersonal networks provides the most fruitful micro-macro bridge'. Today, network analysis is a widespread method not only in sociology, but also in policy and management research. The main goal of network analysis is to identify latent structures of actor relationships, which have developed often unknowingly by the actors. As such, this morphological approach considers social networks as a methodological construction, which leads to significant insights of relational patterns and a deeper understanding of organizations (Nohria, 1992: 5).

On the other hand, there is a strand in current research which considers a network as a planned construct to coordinate interaction among rationally acting organizations. These networks are frequently seen as a hybrid of market and hierarchy based on Williamson's transaction-cost approach (1985). But, as Sydow (1992: 127ff.) and Powell (1990) illustrate, a consideration of a network as a result of transaction costs reduction is not appropriate. These IONs are in fact characterized by features which go beyond the transaction-cost approach. IONs form a horizontal pattern of exchange and rather contrast the organizational structures of markets and hierarchies. Whereas market transactions are based on contracts and hierarchical governance on employment relationships, the normative basis of IONs are the complementary strengths of interdependent actors (Powell, 1990). As a 'particular form of collective action' (Powell, 1990: 322), IONs are characterized by an effective long-term arrangement of cooperating organizations. They support reciprocal learning and information exchange and they serve as protection when access to certain resources is unstable under conditions of uncertainty. Furthermore, IONs offer a 'means of utilizing tacit knowledge and technological innovation' (Powell, 1990: 322). On a theoretical level, Powell (1990: 324) emphasizes three factors as 'critical components of networks' for the formation of sustainable networks: know-how (as a basis for sustainability), demand for speed (as an economic prerequisite) and trust (as a prerequisite for a horizontal cooperation of equal actors).

Whereas Powell considered interorganizational networks as an economically oriented organization, being neither market nor hierarchy, in a sociological perspective, cooperative networks can be considered in a more generalized way. As the network approach focuses on cross-border processes between related actors, this concept enables the researcher to analyze the social phenomena of cooperation, which cannot be described as a system, organization or interaction (Weyer, 2000a: 27). Following this more generalized approach, Weyer defines four key features of IONs:

- Communication across borders of different systems.

- Coordination of different operations. 
- Bridging gaps between different cultures.

- Connection of different interests.

These features correspond to the structures we can find in RST. The different systems are embodied by politics, economy and sport and their sub-systems. Most organizations in the field of sports tourism stem from one of these systems. Furthermore, coordination is crucial in RST on many levels. An example of two operations which have to be coordinated is the development of a new product or service by a RST actor and its marketing within the communication strategy of a destination. As shown before, different organizational cultures are a great challenge in RST. The range of stakeholders is extremely heterogeneous. Some organizations are professionally structured with clear hierarchies (e.g., holiday resorts or commercial sport providers), whereas others (e.g., non-profit sports clubs depending on volunteers) have a completely different organizational culture. Finally, there is a great potential for conflict in RST, since involved actors may have essentially different interests (e.g., outdoor activity providers for mountain biking, jet skiing, canopy tours, etc. vs. environment protection groups or local farmers).

This short sketch illustrates the applicability of the network perspective in grasping the structures to be found in the organization of RST. Most of the network features are commensurable with the structural features of RST. However, in order to achieve a comprehensive grasp of the circumstances and processes that influence the formation of networks in RST, it is necessary to analyze the underlying mechanisms of IONs.

\section{Theoretical Foundation of IONs}

In order to consider the basic functioning of IONs, a limited perspective considering only economic interactions has to be avoided. For the theoretical foundation of IONs it is useful to draw on a sociological standpoint (Weyer, 2000a: 11). The main point in integrating networks into social theory is the duality of action and structure (the micro-macro problem). The network approach is a promising attempt at synthesizing micro and macro issues. As most approaches of social theory focus on either collective structures (e.g., systems theory) or individual action (e.g., rational choice theory), the network approach provides a connection between these two paradigms by focusing on the meso-level.

There have been several attempts to articulate a theory of social networks based on Gidden's (1984) 'theory of structuration'. His explanation of social processes as being influenced by a mixture of mutually dependent macro and micro forces seems to be a possible basis for a theory of social networks. But the main problem with Gidden's approach is his rather abstract conceptualization of the 'duality of structure'. This concept is hard to grasp and remains vague in terms of an operationalization. Hence, it is only of limited use for an empirical analysis of social networks (Ortmann et al., 2000: 352; Walgenbach, 2001: 375; Weyer, 2000b: 238).

Another theoretical starting point could be Esser's (1996: 91ff.) macro-micromacro model (Figure 3). In his action-theoretic approach, the logic of a social 


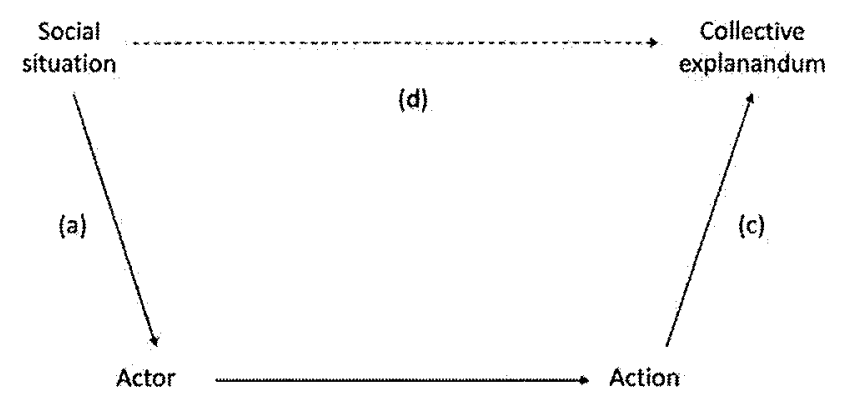

(b)

Figure 3 Macro-micro-macro model (Esser, 1996)

situation prescribes the options of actions for the actor (a) on a macro-level. In a second step, the logic of selection explains the individual choice of action (b) on the micro-level. Finally, the logic of aggregation describes the effect of individual action as collective explanandum (c) on a macro-level. In a diversification of his model, Esser introduced a meso-level to explain so-called social formations on the level of aggregation. These formations could be families, companies, communities, etc. They form a system of interaction on a level between the macro- and microlevel, which is where social networks could possibly be located. However, Esser does not refer to the emergence of social networks as part of the logic of aggregation (Weyer, 2000b: 249).

In a similar explanation of social networks, Kilduff and Tsai (2007) draw on Coleman's (1990: 8) 'bathtub' model, which also served as the basis of Esser's model (1996: 98). Here, individuals are connected in social structures defined by networks. These individual connections influence the actions of an individual, which, in turn, explain the collective behaviour of a social group (network) on a macro-level. Nevertheless, the process of aggregation on a meso-level is not considered and remains unclear. Furthermore, this model attempts to explain the outcomes of a network, considering networks as the independent variable, while leaving out conditions under which network structures develop. However, as Raab and Kenis (2009) argue, a 'network theory' should be able to explain 'the coming into being' (2009: 204), understanding network characteristics as the dependent variable. Thus, this approach provides only a rudimentary link to the network concept as an explanation of the micro-macro linkage. Nevertheless, Kilduff and Tsai's approach, as well as the other approaches, illustrates the potential of the network concept to clarify the connection between the micro- and macro-level.

Focusing on the micro-macro problem, Weyer (2000b) developed a comprehensive approach to explain not only the outcomes, but also the function and emergence of social networks. With this approach Weyer tries not only to explain network characteristics (the network as a dependent variable), but also to provide an operationalizable theory. The main argument is that there is an interdependency of social embedding of individuals (the macro-micro link) and the emergence of social structures (the micro-macro link). Hence, social networks are mediators passing on values 


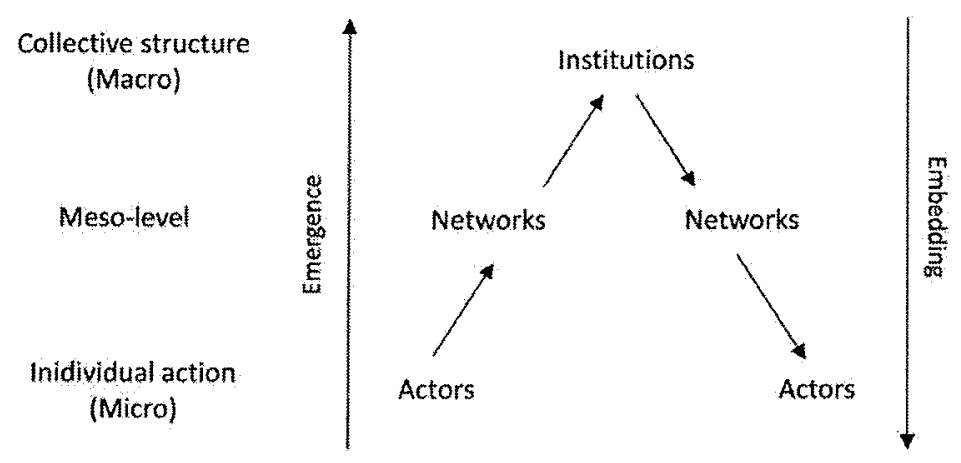

Figure 4 Networks as micro-macro bridge (Weyer, 2000b)

and norms of a social setting to individuals. In a multi-level, reciprocal process, the network provides socialization and control, and imposes sanctions on individuals. This multi-level process is reciprocal. Social construction of reality can be considered as a product of interaction on an individual level. Through interactions, networks as loose and temporary formations of expectations of social behaviour emerge and become social institutions over time (the emergence of social structure). In turn, the norms and expectations of these institutions influence individual action (Figure 4).

Based on this argument, there are three key elements describing the functional mechanisms of a theoretical concept of networks:

- Cooperation.

- Emergence.

- Innovation.

These three correlating principles are the basis for a further specification and operationalization of the functioning of social networks. The first mechanism - social cooperation - can be explained by rational choice: interactions and the exchange of resources take place in expectation of an individual advantage over the long run. Repetition of interaction and exchange leads to a stable and interdependent relation between actors, which can be considered a process of structuring. In this regard, cooperation is a means to structure environmental uncertainty and to create reliable relations. It should be noted that network-based cooperation could also be considered as a mechanism of social capital, allowing people to 'resolve collective problems more easily', as Putnam (2000: 288) puts it. Based on reciprocal trust, cooperative relationships constitute a normative network which helps individuals to achieve different goals.

Emergence, as a second mechanism, describes the formation of a new social structure based on cooperative relationships between individuals. Through individual action, collective action of a higher quality is created. Simply spoken, the whole is greater than its parts. A stabilization of collective action results in an emergent structure. This act of self-generation of social structure, as it is known from systems theory, is a temporary stabilization of social order, based on the interaction of the actors within a system. It is noteworthy that the code of behaviour and norms of this 
system can develop unnoticed by involved actors. Hence, such a network can gain momentum beyond the control of its actors (Kieser \& Woywode, 2001: 276). Concerning the management of networks, this is a crucial point. Emergence therefore describes the self-referential and systemic characteristic of a network as a coherent and autonomous system.

The last mechanism - innovation - depicts the fact that this emergent structure persists only if it is subject to a process of evolution. In a social context, the notion of evolution describes the ability of a social system for assimilation or a progression of behavioural codes and norms. This mechanism of self-organization is caused by a feedback loop or recursive learning, as it is also known from cybernetic approaches (Haggerty, 1988) or systems theory (Probst, 1987: 57). Referring to networks, Weyer $(2000 \mathrm{~b})$ calls this mechanism innovation. In this context, innovation corresponds to the concept of social change, according to which a process of institutionalization is an interaction of structure conserving and changing innovations. This permanent process of evolution enables the organizational survival of a network. The basis for this process is the creation of collective knowledge to stimulate innovation.

Being eclectic in a positive meaning, Weyer's approach to a theory of social networks provides a possibility of bridging the gap between the individual and the system, considering social networks as a form of micro-macro linkage. Explaining systematic processes of individual action and collective structure, this concept overcomes a dichotomous view of social phenomena (cf. Schulz-Schaeffer, 2000: 187). It has to be considered that from this concept of social structure emerging out of individual action (micro-macro), a macro-micro transition can also be derived. In this case, the rules of a social system explain the logic of individual action as a topdown process. Finally, the connection of the micro- and macro-level develops out of a dynamic process of reciprocal action (Kappelhoff, 2000b: 234). On the mesolevel, social networks are the setting of these processes.

It should be mentioned that this function of networks as a 'bridge"' is nothing new in network research. On the contrary, this view has been at the centre of the discussion from the beginning (Granovetter, 1973: 1360). Nohria (1992: 7) gets to the heart of the matter by stating: 'Networks constrain action, and in turn are shaped by them.' However, it should be noted that a network theory is more than just an explanation of the link between two paradigms. Rather, it should be considered as a theoretical level of analysis in its own right to grasp the phenomenon of social and interorganizational networks which cannot be understood as a single actor or a collective structure on the macro-level.

Through the identification of explanatory mechanisms of social networks cooperation, emergence and innovation - Weyer's concept of social networks gives the opportunity of an operationalization of the network. Hence, this conceptually clear approach seems to be suitable for an empirical investigation of networks which goes beyond quantitative network analysis (focusing on the identification of latent structures), but opens the door for qualitative research approaches explaining the functioning of networks. 
To clarify the notion of IONs, a definition and further differentiation is useful. In social network research, Mitchell's (1969: 2) definition is one of the most cited. He defines social networks as

a specific set of linkages among a defined set of persons, with the additional property that the characteristics of these linkages as a whole may be used to interpret the social behavior of the persons involved.

This early definition was the first to include a qualitative aspect of social networks contrasting a metaphoric use of the notion of networks. According to this definition, a group of related actors can be considered a network from the moment the existing linkages among the actors define the social character of this group of actors. Concerning IONs, the actors of a group are represented by social organizations (Kappelhoff, 2000a: 31; Sydow, 1992: 75). Furthermore, IONs can be described as constructs which go beyond operationally closed systems and describe interorganizational cooperation, the structures of which are neither market nor hierarchy, nor both (Schulz-Schaeffer, 2000: 187).

In a further consideration of IONs, different functional alignments can be identified, followed by different logics of action and structural differences. Although there is no consistent typology of networks, there are some prototypical types of IONs: policy networks, strategic networks, regional networks and networks of innovation (Weyer, 2000a: 15) ${ }^{1}$.

Policy networks represent a system for negotiations between public and private actors. Strategic networks are usually market-based alliances of several corporations. Like policy networks, there is one focal actor leading the network. Hence, these are asymmetrical or hierarchical networks with an unequal balance of power. On the other hand, there are symmetrical or heterarchical networks like regional networks. They are characterized by equal relationships, based on the normative mechanism of trust. Powell (1990: 326) describes a common background, in terms of ethnic, geographic, ideological or professional aspects, as a prerequisite for long-term collaboration based on trust. Whereas early regional networks could be described as 'industrial districts' (Marshall, 1927) with the aim of reducing transaction costs, modern regional networks are focused on the exchange of specific regional knowledge (Heidenreich, 2000: 92ff.). Regional networks which are based mainly on knowledge are also called regional networks of innovation. One often-cited example is Silicon Valley in California, USA. In this region, market-oriented, scientific and political actors cooperate successfully, which resulted in worldwide leadership in information technology to the benefit of all involved actors. The approach of regional networks can also be found in current tourism research. Capone (2006: 18) describes such local tourism systems as a long-term network of social and economic actors which is characterized by a regional focus and the provision of a regional tourism product through several small firms which act autonomically in a symmetrical organization. Finally, there are networks of innovation which mainly stimulate and control the development of innovations. The initiators are usually public actors in the fields of economy, education and science (Deitmer, 2004: 43). 

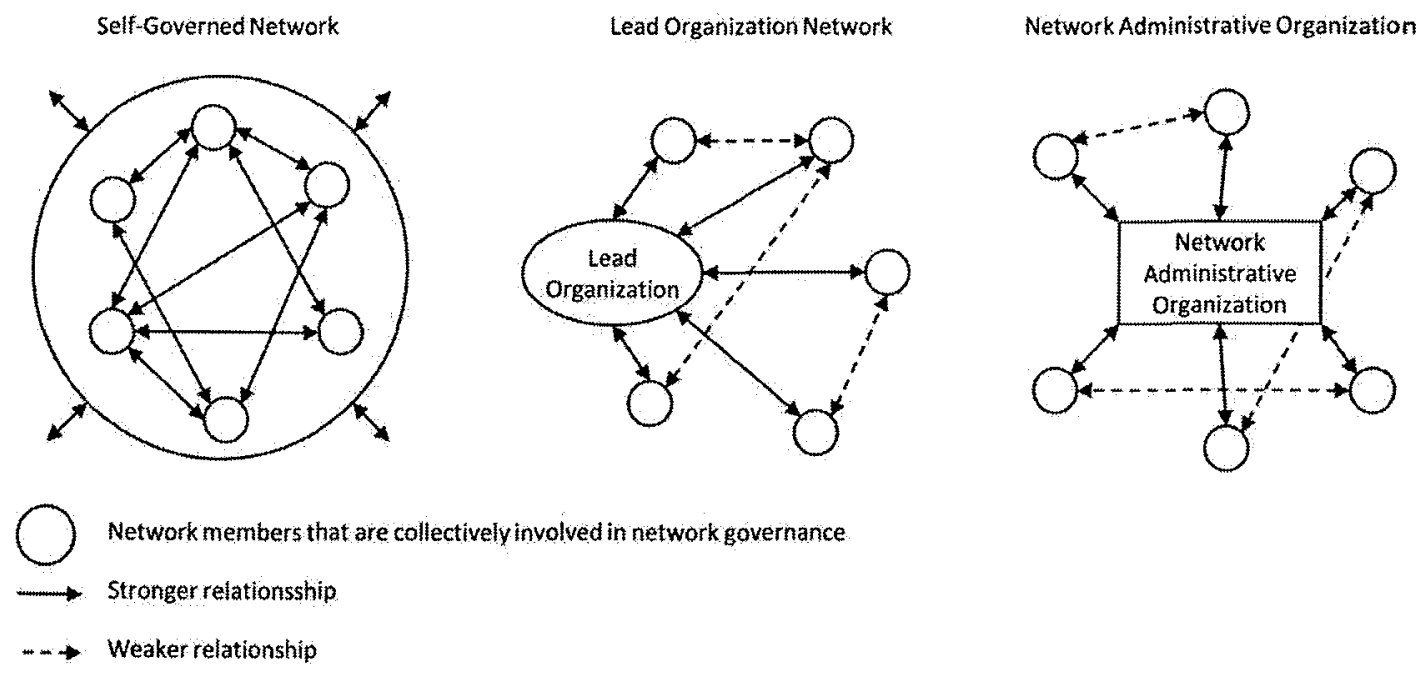

Figure 5 Three governance forms of whole networks (Raab \& Kenis, 2009: 207)

Finally, it is worth looking at differences in the governance of IONs. Although networks cannot be described as a hierarchical form of organization, a control function is needed for effectiveness (Van Raaij, 2006). Kenis and Provan (2009) showed that networks come in various forms and distinguished three different types of network governance: the shared governance network, the lead organization network and the network administrative organization (NAO) network (Figure 5).

The shared governance form comprises several organizations that work collectively but without a distinct governance entity. Although this form of a network is highly inclusive as well as flexible and responsive, it is prone to inefficiency. The lead organization form is most common in the business context and consists mainly of vertical relationships between the lead organization and other network members. In the NAO network, one actor acts as a facilitator or broker who coordinates the activities and key decisions. This separate administrative organization is specifically set up to manage the network and, as Kenis and Provan (2009) point out, usually a non-profit corporation, an unincorporated non-profit or a governmental organization. This network form is more effective than shared governance networks, as well as being more sustainable and legitimate.

Various features of the described network types and their form of governance are relevant in the RST context. In the next section, the type of network we will find in RST and its theoretical basis will be introduced and specified.

\section{RST Networks}

Based on the theoretical assumptions of IONs and specific features of RST, a theoretical concept for RST networks can be developed. Embedded in a theory of social networks, the purpose of this conceptualization is to enable a deeper understanding of the reciprocal interaction of individual action and social structure in RST as a social process. 
Firstly, the term 'RST network' should be made clear. Since the object of investigation is relatively new, an initial definition has to be precise yet also wide-ranging. In an exploratory approach, the intention is to grasp all relevant, manifest and latent aspects of the matter. Consequently, referring to Mitchell's (1969) definition, a RST network is a specific set of linkages between regional actors involved in sports tourism. The network perspective focuses on the interrelationships between the actors. Through these interrelationships between single actors, a stable network structure emerges, which in turn influences the actor's action. According to the described approach to a theory of social networks, the functional mechanisms are cooperation, emergence and innovation.

Furthermore, there are various specific features which can be attributed to RST networks. An important feature is its symmetrical structure, determining RST networks as an equal partnership among autonomous actors. Usually, a RST network is not based on contracts, as is the case in strategic networks between private business organizations (e.g., supplier networks). RST networks form voluntarily, based on the recognition for the need to coordinate activities with other organizations in sports tourism. They are based on mutual trust and they tend to have a rather informal structure with a low to medium threshold level.

Concerning the coordination between the private and the public sector, it is usually a public actor occupying the central position (Weed \& Bull, 1998: 284). In order to integrate all relevant actors (or stakeholders) from the public and private sector, non-profit organizations (NPOs) as well as local residents, it is obvious that only a public actor is able to act as a focal actor without a conflict of interests. In tourist regions, this role is usually fulfilled by a public or quasi-public, local or regional tourism organization (Ullmann, 2000: 27ff.). This corresponds to a finding of Stokes (2006), who studied the process of network-based strategy making for events tourism. In this study, she discovered that it is mainly the public sector that has the capacity to create a tourism network to manage its activities strategically. Hence, referring to Kenis and Provan's (2009) typology of network forms of governance, a RST network can be described as a NAO network since the local or regional tourism organization is usually set up with the task of coordinating the activities of sports tourism within a tourist region.

Although this kind of network is voluntary and is based on a horizontal structure since it consists of autonomous actors, it should be noted that there is not necessarily an equal distribution of power. In sports tourism, heavily dependent on natural resources as it is, there will probably be more powerful actors, even though on an informal basis. An example would be a regional ski-lift operator in a winter sports destination who is likely to be more powerful than one of the local ski schools. In practice, it is likely that there will be a cluster of actors who play a key role in the provision of sports tourism (Tuppen, 2000: 337ff.) and therefore are likely to be more powerful. In any case, the actual distribution of power cannot be generalized since it is dependent on the situation.

Another feature of a RST network is the intermingling of public (regional) and private (economic) interests, which is typical for regional networks and networks of 
innovation. Since the global tourism market is very dynamic and highly competitive, a permanent process of innovation is inevitable. A high level of innovation is necessary to provide system stability and the long-term survival of RST networks.

Apart from the aspect of innovation, a RST network is closest to the type of regional networks. This is not only because of a common regional context as the place for the production of sports tourism, but primarily because the involved actors are dependent on common regional resources. Perrow (1992) described these kinds of networks as 'small-firm networks', and Lynch and Morrison (2007: 48) showed that these kinds of networks are characteristic of networks in tourism. The reason for the dependence on common regional resources is the small size of most firms or actors in tourism, which need support (e.g., in marketing, service or the production of goods). Most importantly, they are dependent on the regional infrastructure. Especially in sports tourism, the infrastructures like transport (streets, railway stations, airports, etc.) and of course sports facilities (marinas, ski-lifts, stadiums, etc.) as well as the use of public space (mountains, lakes, coastlines, etc.) are of great importance.

Another important common resource is specific regional knowledge which enables reciprocal learning processes and provides a basis for regional innovations (Breuer, 2005: 157). Due to the high significance of innovation for regional networks of sports tourism in a highly competitive global market, it seems suitable to specify RST networks as regional networks of innovation (cf. Powell \& Grodal, 2005: 59).

One last constituent feature of RST networks is their ability to integrate various stakeholders. Alongside control, integration is a key element of an action-oriented ION (Weyer, 2000a: 17). In this context, integration refers to a horizontal, vertical and spatial connection of involved actors (Baker, 1992: 399). Especially in RST, where residents have to share sports facilities and natural landscapes, and where commercial interests collide with environmental protection, integration is crucial.

To summarize, the theoretical framework for an understanding of RST networks is based on several principles. First, a RST network is a form of organization (being neither market nor hierarchy) which can best be understood when considered by a meso-level of analysis. It is a group of three or more autonomous actors, which act above the level of individuals (micro-level), but must be understood as a structure below the systems level (macro-level). However, it has to be taken into account that RST networks cannot be considered to be independent of the micro- and macrolevel. In fact, they are constantly being influenced by the interests of single actors as well as superordinated systems (Figure 6).

The main purpose of a RST network is the integration of all relevant actors and the coordination of cooperation in sports tourism within a geographic, cultural and economic entity (the region). The actors, organized within a network of formal and informal relations, are autonomous but interdependent. For the management of a RST network, a NAO, as central or focal actor, is needed to facilitate and coordinate network activities. To avoid conflict of interests, the NAO is ideally a public sector actor.

The functioning of a RST network depends on three mechanisms. Firstly, there must be the will of the single actor to cooperate as the basis for the formation of a relational structure in RST. The prerequisite for cooperative interaction between RST 

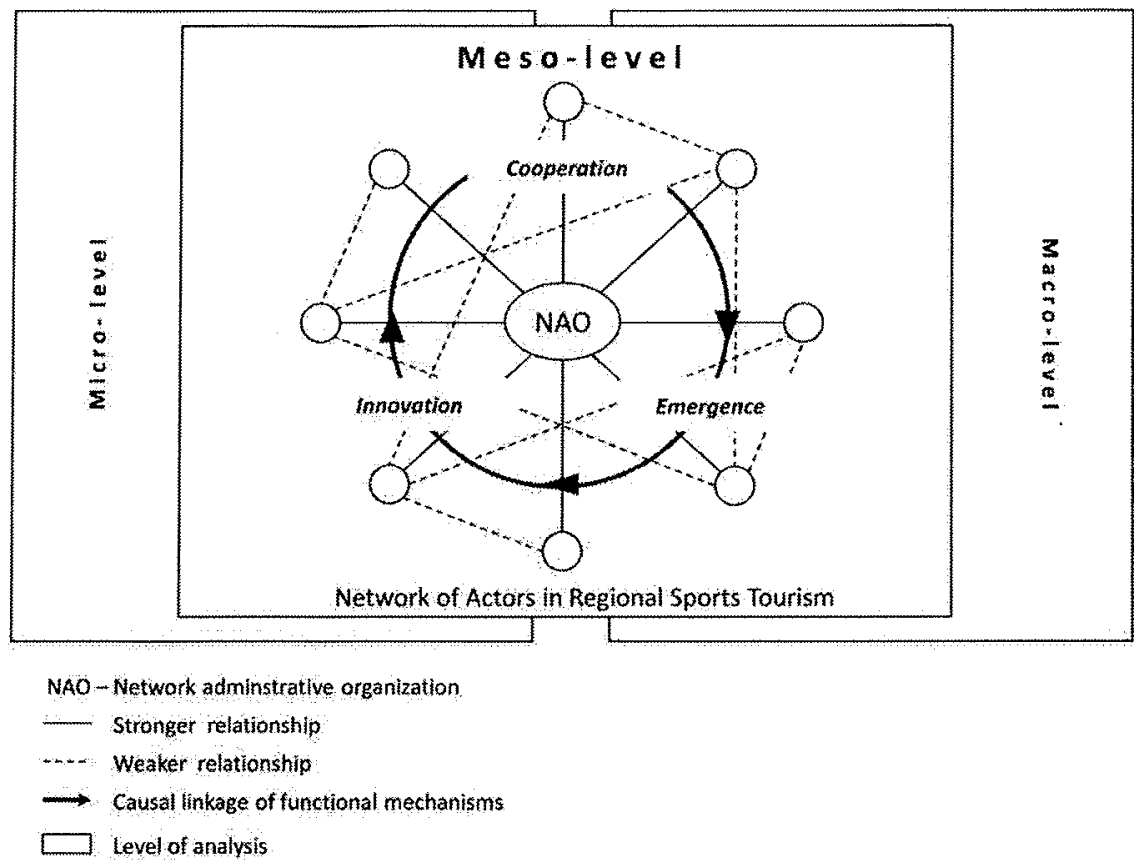

Figure 6 Theoretical framework of RST networks

actors is the expectation of mutual benefits through the relationships. Secondly, through repetition of cooperative interaction, a voluntary network among autonomous actors emerges. To ensure its sustainability and legitimacy, a managing actor (institutionalized management) has to coordinate these interactions. Finally, a mature RST network has to undergo a steady process of evolution to remain stable. Hence, innovation plays a key role and should be addressed consciously in the management process of a RST network.

This theoretical understanding of RST networks is basically a functional approach in that it focuses on the functioning of a RST network. Its purpose is to contribute to an explanation of crucial factors and social patterns which enables the formation and organizational survival of RST networks. Consequently, factors which oppose a functioning and trigger a negative network development should be taken into account as well.

\section{Negative Network Development}

To fully understand the function of RST networks, it is also necessary to be aware of factors which could hinder a positive development. Familiarity with these factors is a prerequisite to prevent negative outcomes. In this section, several factors which have to be taken into account when considering the development of IONs will be discussed (Fürst \& Schubert, 1998: 355ff.).

Probably the most striking problem within a network organization is that of structural holes. While structural holes can be a competitive advantage in a market setting for one actor who thus has exclusive access to the resource of information (Burt, 2000: $353 \mathrm{ff}$.), in a cooperative network, structural holes are counter-productive obstacles. As 
a result of missing links between important actors, a lack of communication and coordination can occur and prevent an effective and efficient functioning of the network. Moreover, there are several empirical findings supporting the argument that tightly knit networks have a positive influence on innovation, which might be due to their ability to exchange implicit, also called 'tacit' knowledge (Powell \& Grodal, 2005: 66).

A similar problem can appear due to a high network selectivity, which can lead to the exclusion of important actors. Too tightly knit networks can become restrictive and consequently prevent input from new members. Restriction triggers stagnation in innovation and finally obstructs the survival of the network (Powell \& Grodal, 2005: 78). In addition, high network selectivity not only inhibits processes of evolution and innovation, but could also exclude important actors needed for the network's assertiveness. In a RST network, this is of particular concern for political actors who are essential considering the need of power and authority to allocate public resources. On the other hand, too many political actors may pose a threat as they could dominate the network and inhibit equality between the members of an ION.

Another important point in ensuring the sustainability of an ION is the need to recur to a higher authority. This will provide the network structure with enough stability even in a dynamic and unstable economic and political environment. As a consequence, IONs must not be dependent on powerful individuals to enable sustainability.

One more structural obstacle emerges in one-dimensional networks. The dominance of one clique, like commercial sport providers, will end in ineffective processes. Since the coordination of differing interests is essential, there is also a need for a balance between powerful actors who are needed for implementation and specialized experts who have the necessary know-how to be productive.

In this context, another possible shortcoming surfaces. In order to stimulate innovation based on the know-how of network members, redundant processes are necessary. Conscious redundancy, that is, an overlapping of responsibilities, activities and especially of information, is a prerequisite for any organizational knowledge creation (Nonaka, 1994: 28). Sharing information supports different interpretations of this information, generating new knowledge leading to innovation. Moreover, shared information forms a basis for mutual trust among the members of a network since redundant information facilitates the interaction among network members. Finally, as a result of a deficient process of knowledge creation and innovation, the sustainability of the network is affected and the ION will struggle to survive. Obsolete mechanisms and a lack of evolutionary processes will lead to an aging of the network, meaning the network and its members will become entangled in obsolete patterns of thinking and acting. In RST, this would result in the loss of competitiveness, with the final outcome of an expiration of the RST network in the long run.

\section{Summary and Implications}

This paper aimed to provide a theoretical foundation of the organizational structure in RST. Since research on organization in sports tourism lacks a substantial theoretical 
body of knowledge, there is a need to work on theoretically profound perspectives which will give the opportunity not only to describe, but also to explain and understand organization in RST.

Hence, the first intention was to contribute to the theory of sports tourism as a relatively new field of research. Since theory as process can be understood as 'an ever-developing entity which can be extended and modified' (Weed, 2006: 227), the discussion in this paper was built on existing theoretical approaches in sports tourism and an elaborate theoretical approach from organizational theory to develop a profound understanding of cooperative networking in RST. Therefore, the term 'RST network', as a regional network of innovation, has been introduced. A RST network describes a complex structure of relations among actors in RST. It serves as a framework which comprises the collective structure of RST as well as individual actions and the interdependency of both levels. The three functional mechanisms of such a network are cooperation, emergence and innovation.

The second intention was to deliver an operationalizable framework for further studies on RST. Only a profound understanding based on a clear concept will be of use for empirical research (Downward, 2005: 306). The presented framework provides a holistic, cross-sectoral perspective, taking into account all stakeholders of a region. By taking recourse to the theory of social networks, several elaborated methodological instruments for empirical research can be applied to analyze RST. With the means of quantitative network analysis, RST networks can be analyzed with respect to the strength of ties, centrality of actors, density of networks or structural holes. Qualitative network analysis will open the door to explaining and understanding RST networks through an analysis of latent mechanisms, as they were discussed before. Moreover, an explanation of the interrelationship between individual action and collective structure will help to better understand organizational outcomes in RST.

Finally, the concept of a RST network provides several management implications. As described, the crucial point for managing RST networks is to recognize the importance of the relations in a network. It is not only information, in terms of coordination of cooperation, conflict resolution and knowledge generation, but it is also trust built upon strong mutual relationships, which is crucial for a successful network. A horizontal network like in RST strongly depends upon a culture of trust. Consequently, relationship management is the key to cooperation in the RST network. Furthermore, sustainability is highly significant for the development of emergent structures of a RST network. This is why managers in RST should be aware of factors that could trigger a negative development of such a network, such as structural holes. However, the most important factor for sustainability is innovation. Innovation stimulates an evolutionary process which is a prerequisite for the RST network's successful survival in the long run.

Concerning the practical management in RST networks, it has to be taken into account that a voluntary RST network consists of many informal or weaker relationships. This will affect the management in that most decisions are dependent on the will of the involved actors to cooperate. Hence, an integrating strategy and intense processes of communication will be necessary to manage a RST network effectively. 
In summary, the consideration of organization in RST from the point of view of social network theory provides new insights into this relatively recent area of inquiry. While the key problem - cooperation among a highly diverse group of actors - has been recognized in several studies, no satisfying explanation which can lead to an understanding of relevant processes and structures in RST has been made thus far. In this paper, a conceptual framework has been developed which aims not only to provide a theoretical explanation of organization in RST, but also to lay a foundation for further empirical research and implications for the management of RST.

\section{Note}

[1] This typology of networks does not represent the only possible categorization. In fact, there are plenty of typologies. For example, Powell \& Grodal (2005: 61) differentiate between informal, project, regional and business networks. Another type of network which has been subject to several studies is the virtual network (Sydow, 2003: 304).

\section{References}

Augustyn, M. (1996). Opportunities for cooperative sport tourism marketing. In C. Pigeassou \& R. Ferguson (Eds.), The World of Sport Management and Sport Management throughout the World: Fourth European Congress on Sport Management; First International Sport Management Alliance Conference, 2-5 October 1996. Proceedings. EASM: Montpellier.

Baker, W.E. (1992). The network organization in theory and practice. In N. Nohria \& R.G. Eccles (Eds.), Networks and Organizations. Structure, Form, and Action, pp. 397-429. Boston: Harvard Business School Press.

Bonetti, E., Petrillo, C.S., \& Simoni, M. (2006). Tourism system dynamics: A multi-level destination approach. In L. Lazzeretti \& C.S. Petrillo (Eds.), Tourism Local Systems and Networking, pp. S. 111-34. Amsterdam: Elsevier.

Breuer, C. (2004). Die Steuerung sporttouristischer Attraktivität von Regionen durch Netzwerkstrategien. In J. Hinsching \& W. Steingrube (Eds.), Sporttourismus und Region. Das Beispiel Mecklenburg-Vorpommern, pp. 19-32. Hamburg: Czwalina.

Breuer, C. (2005). Steuerbarkeit von Sportregionen. Schorndorf: Hofmann.

Burt, R.S. (2000). The network structure of social capital. In R.I. Sutton \& B.M. Staw (Eds.), Research in Organizational Behavior, Vol 22, pp. 345-423. Greenwich, CT: JAI Press.

Capone, F. (2006). Systemic approaches for the analysis of tourism destinations: Towards the tourist local systems. In L. Lazzeretti \& C.S. Petrillo (Eds.), Tourism Local Systems and Networking, pp. 7-24. Amsterdam: Elsevier.

Coleman, J.S. (1990). Foundations of Social Theory. Cambridge: Belknap Press.

Commonwealth of Australia - Department of Industry, Science and Resources (2000). Towards a National Sports Tourism Strategy (Draft). Retrieved 2 June 2006 from http://www.ausport. gov.au/fulltext/2000/feddep/SportTourismStrategy.pdf

Degenne, A. \& Forsé, M. (1999). Introducing Social Networks. London: Sage.

Deitmer, L. (2004). Management regionaler Innovationsnetzwerke. Evaluation als Ansatz zur Effizienzsteigerung regionaler Innovationsprozesse. Baden-Baden: Nomos.

Downward, P. (2005). Critical (realist) reflection on policy and management research in sport, tourism and sports tourism. European Sport Management Quarterly, 5(3), 303-320.

Dreyer, A. (2004). Sport und Tourismus. In A. Krüger \& A. Dreyer (Eds.), Sportmanagement, pp. 327-376. Munich: Oldenbourg. 
Esser, H. (1996). Soziologie. Allgemeine Grundlagen, 2nd edn. Frankfurt a.M.: Campus.

Freeman, E.R., \& Reed, D.L. (1983). Stockholder and stakeholders: A new perspective on corporate governance. California Management Review, 25(3), 88-106.

Fürst, D., \& Schubert, H. (1998). Regionale Netzwerke. Zur Rolle von Netzwerken in regionalen Umstrukturierungsprozessen. Raumforschung und Raumordnung, 5/6, 352-361.

Gibson, H. (2002). Sport tourism at a crossroad? Considerations for the future. In S. Gammon \& J. Kutzman (Eds.), Sport Tourism: Principles and Practice. Eastbourne: LSA.

Gibson, H. (2004). Moving beyond the 'what is and who' of sport tourism to understanding why"'. Journal of Sport Tourism, 9(3), 247-265.

Giddens, A. (1984). The Constitution of Society. Outline of the Theory of Structuration. Cambridge: Polity Press.

Glyptis, S. (1982). Sport and Tourism in Western Europe. London: British Travel Educational Trust.

Granovetter, M.S. (1973). The strength of weak ties. American Journal of Sociology, 78(6), 1360-1380.

Haggerty, T.R. (1988). Designing control and information systems in sport organizations: A cybernetic perspective. Journal of Sport Management, 2(1), 53-63.

Hall, C.M. (2005). Sport tourism planning. In J. Higham (Ed.), Sport Tourism Destinations. Issues, Opportunities and Analysis, pp. 103-121. Oxford: Elsevier.

Hautbois, C., Ravenel, L., \& Durand, C. (2003). Sport tourism and local economic development: The importance of an initial diagnosis of supplier's geographical concentration: A case study of France. Journal of Sport Tourism, 8(4), 240-259.

Heidenreich, M. (2000). Regionale Netzwerke in der globalen Wissensgesellschaft. In J. Weyer (Ed.), Soziale Netzwerke: Konzepte und Methoden der sozialwissenschaftlichen Netzwerkforschung, pp. 87-110. Munich: Oldenbourg.

Hinch, T., Jackson, E., Hudson, S., \& Walker, H. (2006). Leisure constraint theory and sport tourism. In H. Gibson (Ed.), Sport Tourism. Concepts and Theories, pp. 10-31. London: Routledge.

Kappelhoff, P. (2000a). Der Netzwerkansatz als konzeptueller Rahmen für eine Theorie interorganisationaler Netzwerke. In J. Sydow \& A. Windeler (Eds.), Steuerung von Netzwerken. Konzepte und Praktiken, pp. 25-57. Wiesbaden: Westdeutscher Verlag.

Kappelhoff, P. (2000b). Rational Choice, Macht und korporative Organisation der Gesellschaft. In G. Ortmann, J. Sydow \& K. Türk (Eds.), Theorien der Organisation. Die Rückkehr der Gesellschaft, 2. durchgesehene Aufl., pp. 218-258. Wiesbaden: Westdeutscher Verlag.

Kenis, P. \& Provan, K.G. (2009). Towards an exogenous theory of public network performance. Public Administration, 87(3), 440-456.

Kieser, A., \& Woywode, M. (2001). Evolutionstheoretische Ansätze. In A. Kieser (Ed.), Organisationstheorien, 4. Aufl., S. 253-286. Stuttgart: Kohlhammer.

Kilduff, M., \& Tsai, W. (2007). Social Networks and Organizations. London: Sage.

Lazzeretti, L., \& Petrillo, C.S. (Eds.). (2006). Tourism Local Systems and Networking. Amsterdam: Elsevier.

Lynch, P., \& Morrison, A. (2007). The role of networks. In E.J. Michael (Ed.), Micro-clusters and Networks. The Growth of Tourism, pp. 43-62. Amsterdam: Elsevier.

Marshall, A. (1927). Principles of Economics. An Introductory Volume 8th edn. London: Macmillan.

Mayntz, R. (1992). Modernisierung und die Logik von interorganisatorischen Netzwerken. Journal für Sozialforschung, 32(1), 19-32.

Michael, E.J. (Ed.). (2007). Micro-clusters and Networks: The Growth of Tourism. Amsterdam: Elsevier.

Mitchell, J.C. (1969). The concept and use of social networks. In J.C. Mitchell (Ed.), Social Networks in Urban Situations, pp. 1-32. Manchester University Press.

Nohria, N. (1992). Introduction: Is a network perspective a useful way of studying organizations? In N. Nohria \& R.G. Eccles (Eds.), Networks and Organizations. Structure, Form, and Action, pp. 1-22. Boston: Harvard Business School Press. 
Nonaka, I. (1994). A dynamic theory of organizational knowledge creation. Organization Science, $5(1), 14-37$.

Ortmann, G., Sydow, J., \& Windeler, A. (2000). Organisation als reflexive Strukturation. In G. Ortmann, J. Sydow \& K. Türk (Eds.), Theorien der Organisation. Die Rückkehr der Gesellschaft, pp. 315-354. Wiesbaden: Westdeutscher Verlag.

Perrow, C. (1992). Small-firm networks. In N. Nohria \& R.G. Eccles (Eds.), Networks and Organizations. Structure, Form and Action, pp. 445-470. Boston: Harvard Business School Press.

Powell, W.W. (1990). Neither market nor hierarchy: Network forms of organization. Research in Organizational Behavior, 12, 295-336.

Powell, W.W., \& Grodal, S. (2005). Networks of innovators. In J. Fagerberg (Ed.), The Oxford Handbook of Innovation. Oxford University Press.

Probst, G. (1987). Selbstorganisation. Ordnungsprozesse in sozialen Systemen aus ganzheitlicher Sicht. Berlin: Paul Parey.

Putnam, R.D. (2000). Bowling Alone. The Collapse and Revival of American Community. New York: Simon \& Schuster.

Raab, J., \& Kenis, P. (2009). Heading towards a society of networks. Empirical development and theoretical challenges. Journal of Management Inquiry, 18(3), 198-210.

Rhodes, R.A.W. (1981). Control and Power in Central-Local Government Relations. Farnborough: Gower.

Ritchie, B., \& Adair, D. (2004). Sport tourism: An introduction and overview. In B. Ritchie \& D. Adair (Eds.), Sport Tourism. Interrelationships, Impacts and Issues, pp. 1-29. Clevedon: Channel View.

Schulz-Schaeffer, I. (2000). Akteur-Netzwerk-Theorie. Zur Koevolution von Gesellschaft, Natur und Technik. In J. Weyer (Ed.), Soziale Netzwerke. Konzepte und Methoden der sozialwissenschaftlichen Netzwerkforschung, pp. 187-209. Munich: Oldenbourg.

Schwark, J. (2007). Sporttourismus - Stand und Entwicklung eines neuen Forschungsfeldes. Sportwissenschaft, 37(3), 279-295.

Sinz, M. (1995). Region. In P. Treuner (Ed.), Handwörterbuch der Raumordnung, pp. 805-806. Hannover: ARL.

Standeven, J., \& De Knop, P. (1999). Sport Tourism. Champaign: Human Kinetics.

Stokes, R. (2006). Network-based strategy making for events tourism. European Journal of Marketing, $40(5 / 6), 682-695$.

Sydow, J. (1992). Strategische Netzwerke. Evolution und Organisation. Wiesbaden: Gabler.

Sydow, J. (2003). Management von Netzwerkorganisationen - Stand der Forschung. In J. Sydow (Ed.), Management von Netzwerkorganisationen, pp. 293-354. Wiesbaden: Gabler.

Tuppen, J. (2000). The restructuring of winter sports resorts in the French Alps: problems, processes and policies. International Journal of Tourism Research, 2(5), 327-344.

Ullmann, S. (2000). Strategischer Wandel im Tourismus. Dynamische Netzwerke als Zukunftsperspektive. Wiesbaden: Deutscher Universitäts-Verlag.

Van Raaij, D.P.A.M. (2006). Norms network members use: An alternative perspective for indicating network success of failure. International Public Management Journal, 9(3), 249-270.

Walgenbach, P. (2001). Giddens' Theorie der Strukturierung. In A. Kieser (Ed.), Organisationstheorien, pp. 355-375. Stuttgart: Kohlhammer.

Wäsche, H., \& Woll, A (2010). Gesundheitssport und Tourismus. Zur Bedeutung des Gesundheitssports im regionalen Sporttourismus. In R. Kähler (Ed.), Ökonomische Perspektiven von Sport und Gesundheit. Schorndorf: Hofmann.

Weed, M. (2001). Towards a model of cross-sectoral policy development in leisure: The case of sport and tourism. Leisure Studies, 20(2), 125-141.

Weed, M. (2003). Why the two won't tango! Explaining the lack of integrated policies for sport and tourism in the UK. Journal of Sport Management, 17(3), 258-283. 
Weed, M. (2005). A grounded theory of the policy process for sport and tourism. Sport in Society, $8(2), 356-377$.

Weed, M. (2006). Sports tourism research 2000-2004: A systematic review of knowledge and a metaevaluation of methods. Journal of Sport \& Tourism, 11(1), 5-30.

Weed, M. (2008a). General introduction. In M. Weed (Ed.), Sport \& Tourism. A Reader, pp. 1-6. London: Routledge.

Weed, M. (2008b). Sports tourism theory and method - Concepts, issues and epistemologies. In M. Weed (Ed.), Sport \& Tourism. A Reader, pp. 12-23. London: Routledge.

Weed, M., \& Bull, C. (1997). Integrating sport and tourism: A review of regional policies in England. Progress in Tourism and Hospitality Research, 3(2), 129-148.

Weed, M., \& Bull, C. (1998). The search for a sport-tourism policy network. In M. Collins \& I. Cooper (Eds.), Leisure Management: Issues and Applications, pp. 277-298. Wallingford: CABI.

Weed, M., \& Bull, C. (2004). Sports Tourism. Participants, Policy and Providers. Amsterdam: Elsevier Butterworth-Heinemann.

Weed, M., \& Bull, C. (2009). Sports Tourism. Participants, Policy and Providers 2nd edn. Amsterdam: Elsevier Butterworth-Heinemann.

Weyer, J. (2000a). Zum Stand der Netzwerkforschung in den Sozialwissenschaften. In J. Weyer (Ed.), Soziale Netzwerke: Konzepte und Methoden der sozialwissenschaftlichen Netzwerkforschung, pp. 3-34. Munich: Oldenbourg.

Weyer, J. (2000b). Soziale Netzwerke als Mikro-Makro-Scharnier. Fragen an die soziologische Theorie. In J. Weyer (Ed.), Soziale Netzwerke: Konzepte und Methoden der sozialwissenschaftlichen Netzwerkforschung, pp. 237-254. Munich: Oldenbourg.

Wilks, S., \& Wright, M. (1987). Conclusion: Comparing government-industry relations: States, sectors, and networks. In S. Wilks \& M. Wright (Eds.), Comparative Government-Industry Relations. Western Europe, the United States and Japan, pp. 274-313. Oxford: Clarendon.

Williamson, O.E. (1985). The Economic Institutions of Capitalism. New York: Free Press. 